\title{
SOLIDIFICAÇÃO UNIDIRECIONAL TRANSITÓRIA, MICROESTRUTURA E INTERMETÁLICOS DE LIGAS SN-NI*
}

\author{
Clarissa Barros da Cruz ${ }^{1}$ \\ Rafael Kakitani ${ }^{1}$ \\ Marcella Gautê Cavalcante Xavier ${ }^{2}$ \\ Bismarck Luiz Silva ${ }^{3}$ \\ Noé Cheung ${ }^{4}$ \\ José Eduardo Spinelli ${ }^{5}$
}

\section{Resumo}

As ligas livres de chumbo (Lead-free solder alloys) potencialmente utilizáveis em processos de soldagem branda, tais como as ligas à base de $\mathrm{Sn}$, vêm sendo estudadas como alternativas para substituir as ligas do sistema $\mathrm{Sn}-\mathrm{Pb}$. Em vista disto, o presente trabalho, aborda tanto a análise das características microestruturais formadas durante a solidificação transitória das ligas eutética $\mathrm{Sn}-0,2 \% \mathrm{Ni}$ e hipereutética $\mathrm{Sn}-0,5 \% \mathrm{Ni}$, quanto a determinação das suas respectivas correlações com os parâmetros térmicos de solidificação: velocidade da isoterma eutética $\left(\mathrm{V}_{E}\right)$ e taxa de resfriamento $\left(\dot{T}_{E}\right)$. Para tanto, as ligas foram solidificadas unidirecionalmente no sentido vertical ascendente e em regime transiente, e caracterizadas por técnicas de microscopias ótica e eletrônica de varredura. Na liga hipereutética $\mathrm{Sn}-0,5 \% \mathrm{Ni}$, o aumento da quantidade de $\mathrm{Ni}$ na liga influenciou tanto o comportamento térmico quanto o espaçamento celular $\left(\lambda_{c}\right)$, proporcionando maiores valores de $\dot{T}_{E}$, porém, $\lambda_{c}$ mais grosseiros. $\mathrm{O}$ intermetálico $\mathrm{NiSn}_{4}$ formou-se na região eutética de ambas as ligas, enquanto que na liga $\mathrm{Sn}-0,5 \% \mathrm{Ni}$, as fases primárias identificadas por EDS$\mathrm{MEV}$ foram $\mathrm{NiSn}_{4}$ e $\mathrm{Ni}_{3} \mathrm{Sn}_{4}$. A transição morfológica celular/dendrítica( $\dot{T}_{\mathrm{E}}>1,2^{\circ} \mathrm{C} / \mathrm{s}$ ) ocorreu apenas para a liga eutética, enquanto que as células regulares da liga hipereutética deram origem as células do tipo placas $\left(\dot{T}_{\mathrm{E}}>1,4^{\circ} \mathrm{C} / \mathrm{s}\right)$.

Palavras-chave:Ligas livres de chumbo; Solidificação transitória; Microestrutura.

\section{TRANSIENT UNIDIRECTIONAL SOLIDIFICATION, MICROSTRUCTURE AND INTERMETALLICS OF SN-NI ALLOYS}

\section{Abstract}

Lead-free solder alloys potentially used in soft solder processes, such as Sn-based alloys, have been studied as alternative to $\mathrm{Sn}-\mathrm{Pb}$ alloys. Therefore, this work aims not only analyze the microstructural features formed during the transient solidification of eutectic Sn-0.2wt.\%Ni and hypereutectic Sn-0.5wt.\%Ni alloys, but also the determination of their respective correlations with the thermal parameters: growth $\left(V_{E}\right)$ and cooling rates $\left(\dot{T}_{E}\right)$. The alloys were directionally solidified in upward direction and unsteady-state regime, and characterized by optic and scanning electronic microscopes techniques. Concerning the hypereutectic Sn-0.5wt.\%Ni, the increase of $\mathrm{Ni}$ content influenced both thermal behavior and cellular spacing $\left(\lambda_{c}\right)$, providing higher values of $\dot{T}_{E}$ although $\lambda_{c}$ become more coarse. The NiSn 4 intermetallic formed in the eutectic region of both alloys, whilst in the $\mathrm{Sn}-0.5 \mathrm{wt} . \% \mathrm{Ni}$, the primary phases identified by EDS-SEM were $\mathrm{NiSn}_{4}$ and $\mathrm{Ni}_{3} \mathrm{Sn}_{4}$. The morphologic transition cellular/dendritic $\left(\dot{T}_{E>} 1,2^{\circ} \mathrm{C} / \mathrm{s}\right.$ ) occurred only in the eutectic alloy, although regular cells in the hypereutectic alloy turned into plate-like cells $\left(\dot{T}_{\mathrm{E}}>1,4^{\circ} \mathrm{C} / \mathrm{s}\right)$.

Keywords: Lead-free alloys; Transient solidification; Microstructure. 
1 Engenheiro Mecânico, Doutorando, Departamento de Engenharia de Manufatura e Materiais, Universidade Estadual de Campinas, Campinas, São Paulo e Brasil.

2 Engenheira Metalurgista, Mestrando, Departamento de Engenharia de Materiais, Universidade Federal de São Carlos, São Carlos, São Paulo e Brasil.

3 Engenheiro de Materiais, Doutor, Professor, Departamento de Engenharia de Materiais, Universidade Federal do Rio Grande do Norte, Natal, Rio Grande do Norte, Brasil.

4 Engenheiro Mecânico, Doutor, Professor, Departamento de Engenharia de Manufatura e Materiais, Universidade Estadual de Campinas, Campinas, São Paulo e Brasil.

5 Engenheiro Mecânico, Doutor, Professor, Departamento de Engenharia de Materiais, Universidade Federal de São Carlos, São Carlos, São Paulo e Brasil. 


\section{INTRODUÇÃO}

Desde o início do século XXI, novas políticas foram adotadas a fim de combater o uso de elementos tóxicos presentes nos componentes eletrônicos [1]. Ligas livres de chumbo (Lead-free solder alloys) potencialmente utilizáveis em processos de soldagem branda vêm sendo estudadas, portanto, como alternativas para substituir as ligas do sistema $\mathrm{Sn}-\mathrm{Pb}$ comumente empregadas na união dos circuitos eletrônicos modernos [2].

Pesquisas ligadas ao desenvolvimento de novos sistemas de ligas para soldagem estão em andamento e por sua vez, devem abordar as características microestruturais formadas durante a solidificação [4-6]. Por meio de experimentos de solidificação direcional em condições transitórias de extração de calor, as microestruturas dos lingotes resultantes dependem basicamente da composição química e dos parâmetros térmicos de solidificação (taxa de resfriamento - Tं e v velocidade de solidificação) [7].

Dentre esses novos sistemas, destacam-se as ligas à base de Sn por apresentar excelente fluidez e temperaturas de trabalho ideais, tais como as ligas do sistema $\mathrm{Sn-Cu}$ [8-10] e Sn-Cu-Ag [11-13]. Embora estas ligas tenham sido amplamente investigadas e compreendidas, as mesmas possuem um custo elevado abrindo espaço para outras alternativas, como as ligas do sistema Sn-Ni,tendo em vista que, existe pouca pesquisa dedicada à solidificação desse sistema [14].

Dessa forma, o presente trabalho visa analisar as ligas eutética $\mathrm{Sn}-0,2 \% \mathrm{Ni}$ e hipereutética $\mathrm{Sn}-0,5 \% \mathrm{Ni}$ solidificadas unidirecionalmente em regime transitório de fluxo de calor aproximando-se das condições industriais de processamento. Estas ligas foram avaliadas quanto ao seu desenvolvimento microestrutural com suas respectivas correlações com os parâmetros térmicos de solidificação: velocidade da isoterma eutética $\left(\mathrm{V}_{\mathrm{E}}\right)$ e taxa de resfriamento $\left(\dot{T}_{\mathrm{E}}\right)$. A caracterização microestrutural foi realizada através das técnicas de microscopia ótica e microscopia eletrônica de varredura, com a medição dos espaçamentos celulares $\left(\lambda_{c}\right)$ ao longo dos lingotes. Correlações experimentais dos parâmetros térmicos com parâmetros microestruturais são discutidas.

\section{MATERIAIS E MÉTODOS}

As ligas $\mathrm{Sn}-0,2 \% \mathrm{Ni}$ e $\mathrm{Sn}-0,5 \% \mathrm{Ni}$ (composições em massa) foram preparadas a partir de metais comercialmente puros: $\mathrm{Sn}-99,94 \% \mathrm{Ni}-99,99 \%$; e obtidas por meio do dispositivo de solidificação unidirecional vertical ascendente. Este aparato, mostrado na Figura 1, permite que o fluxo de calor seja vertical e extraído pela base (chapamolde) devido à refrigeração da mesma. 


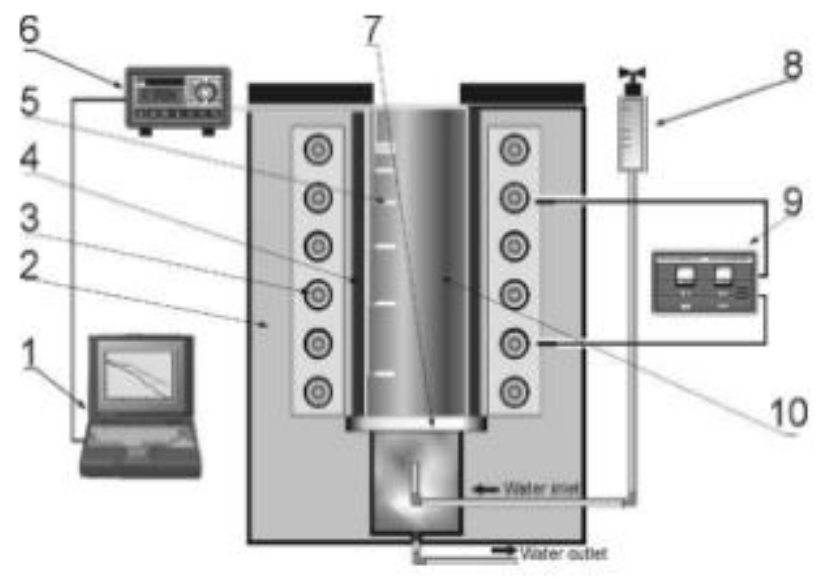

Figura 1.Modelo esquemático do sistema de solidificação unidirecional vertical ascendente: 1) computador e software de aquisição; 2) material isolante; 3) resistências elétricas; 4)molde bipartido; 5) termopares; 6) registrador de temperatura; 7) chapa-molde; 8) rotâmetro de água; 9) controlador de temperatura; 10) metal fundido [15].

As ligas eutéticas e hipereutéticas foram fundidas e homogeinizadas em um forno tipo mufla e posteriormente vertidas no interior de um molde bipartido de aço inoxidável, tendo sido suas temperaturas controladas até que a refrigeração forçada à água fosse acionada na parte inferior da chapa-molde de aço carbono 1020. Uma série de termopares do tipo $\mathrm{J}$, dispostos em diferentes posições ao longo da lingoteira,foi utilizada para o registro térmico do processo.

Após completa solidificação, os lingotes foram seccionados na direção longitudinal para a análise macroestrutural. Posteriormente, as amostras, da secção transversal, nas posições $5,10,15,20,25,30,40,50,60$ e $70 \mathrm{~mm}$ a partir da interface metal/molde, foram preparadas para observação microscópica.

Ao utilizar o reagente químico Keller $\left(2,5 \mathrm{~mL} \mathrm{HNO}_{3}+1,5 \mathrm{~mL} \mathrm{HCl}+1,0 \mathrm{~mL} \mathrm{HF}+95 \mathrm{~mL}\right.$ $\mathrm{H}_{2} \mathrm{O}$ ) e uma outra solução para ataque profundo de $5 \%$ (vol) $\mathrm{NaOH}$ e $3,5 \%(\mathrm{vol})$ Ortonitrofenol em $\mathrm{H}_{2} \mathrm{O}$, foi possíve Iverificar, por meio dos microscópios ótico Olympus BX41M-LED e eletrônico de varredura INSPECT S50, as microestruturas características dessas ligas. As medidas de espaçamentos celulares $\left(\lambda_{c}\right)$, para diversas posições transversais, foram realizadas de acordo com os métodos quantitativos do intercepto [3] e do triângulo [16].

\section{RESULTADOS E DISCUSSÃO}

Os registros das temperaturas durante a solidificação das ligas $\mathrm{Sn}-0,2 \% \mathrm{Ni}$ e $\mathrm{Sn}$ $0,5 \% \mathrm{Ni}$ estão representados na forma de perfis térmicos (Figura 2), demonstrando que, para as posições mais próximas da interface metal/molde, há uma queda mais acentuada da temperatura, devido à maior proximidade com a superfície de extração de calor. O resfriamento mais brando nas posições mais afastadas da interface é devido à camada já solidificada do metal e o gap formado pela contração do metal, que são resistências térmicas para o fluxo de calor. 
(a)

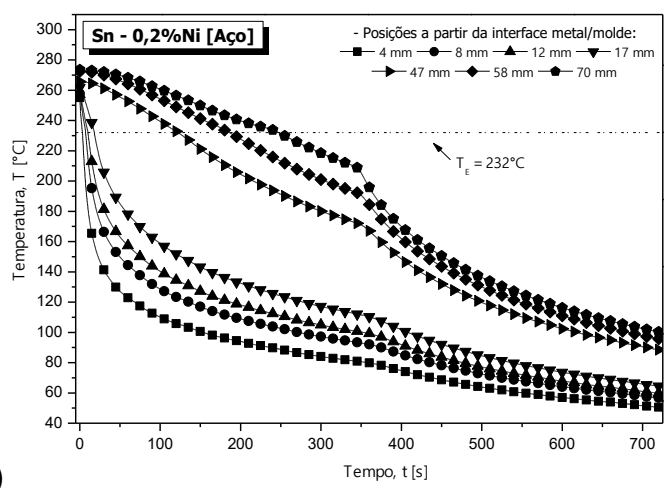

(b)

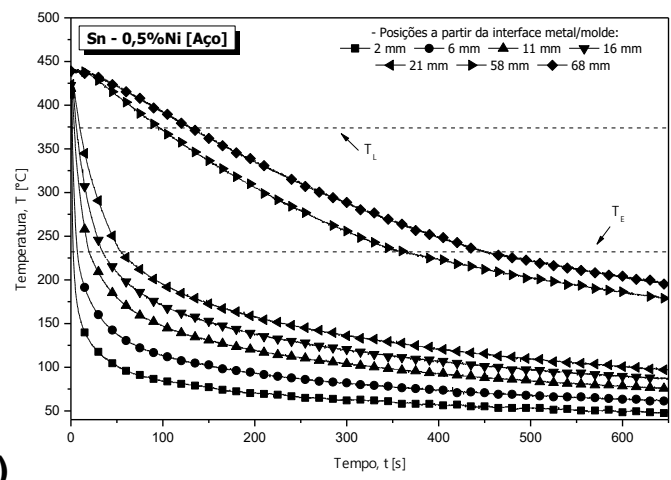

Figura 2.Perfis térmicos das ligas a) $\mathrm{Sn}-0,2 \% \mathrm{Ni}$ e b) $\mathrm{Sn}-0,5 \% \mathrm{Ni}$ solidificadas direcionalmente.

A Figura 3 ilustra os perfis de taxa de resfriamento (广்) em relação à posição da interface metal/molde para as duas ligas, sendo que, no caso da liga $\mathrm{Sn}-0,5 \% \mathrm{Ni}$ (hipereutética), os perfis de Tं foram calculados referentes às temperaturas liquidus e eutética, obtendo-se $\dot{T}_{L}$ e $\dot{T}_{E}$, respectivamente. De imediato, verifica-se que os valores de $\dot{T}_{\llcorner}$são muito superiores às $\dot{T}_{E}$, indicando que, possivelmente, a maior quantidade de $\mathrm{Ni}$ na liga contribui para melhorar a molhabilidade entre o metal líquido e o molde, já que essa diferença é mais significativa nas posições próximas da base [17]. Em relação à $\dot{T}_{E}$, inicialmente, a liga hipereutética apresenta uma maior taxa de resfriamento em comparação com a liga eutética, e partir da posição $10 \mathrm{~mm}$, os perfis das duas ligas demonstram grande semelhança.

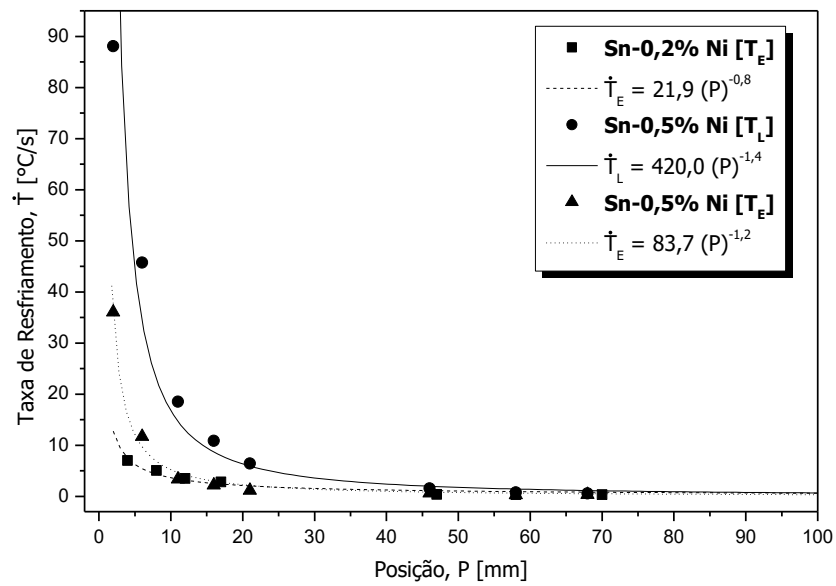

Figura 3.Perfis experimentaisdas taxas de resfriamento ( $\dot{T}_{L}$ e $\left.\dot{T}_{E}\right)$ das ligas $\mathrm{Sn}-0,2 \% \mathrm{Ni}$ e Sn-0,5\%Ni.

Comportamento semelhante é encontrado para a velocidade de solidificação (Figura 4), na qual a velocidade da isoterma liquidus ( $\left.V_{L}\right)$ da liga $\mathrm{Sn}-0,5 \% \mathrm{Ni}$ é muito superior à velocidade da isoterma eutética $\left(V_{E}\right)$ da liga $\mathrm{Sn}-0,2 \% \mathrm{Ni}$. Os perfis experimentais de $V_{E}$ das duas ligas são próximos. 


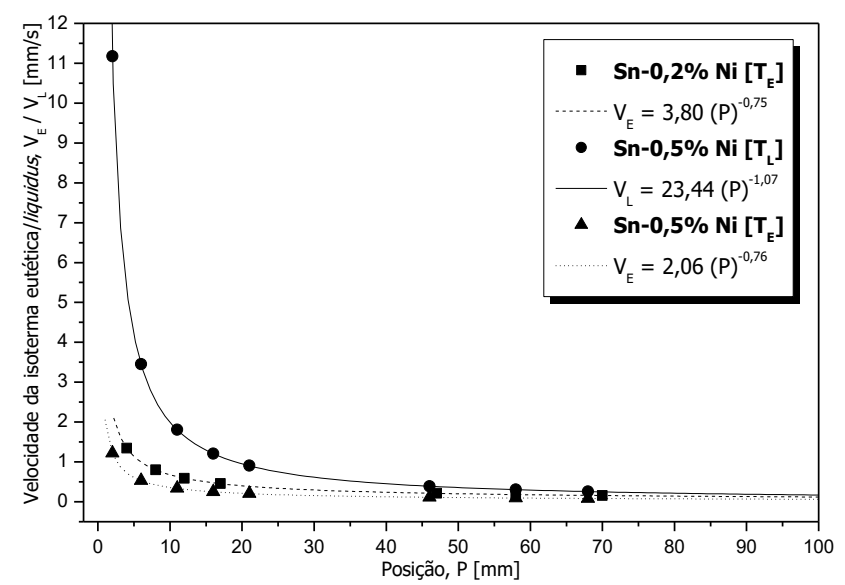

Figura 4.Perfis experimentais das velocidades dasisotermasliquidus $\left(\mathrm{V}_{\mathrm{L}}\right)$ e eutética $\left(\mathrm{V}_{\mathrm{E}}\right)$ obtidos para as ligas $\mathrm{Sn}-0,2 \% \mathrm{Ni}$ e $\mathrm{Sn}-0,5 \% \mathrm{Ni}$.

As macroestruturas e microestruturas típicas das ligas Sn-0,2\%Ni e Sn-0,5\%Ni estão ilustradas nas Figuras 5 e 6 , respectivamente, evidenciando grãos colunares e paralelos em relação à direção de extração de calor. As placas mais escuras na Figura 6 estão indicadas e representam a fase primária da liga hipereutética.

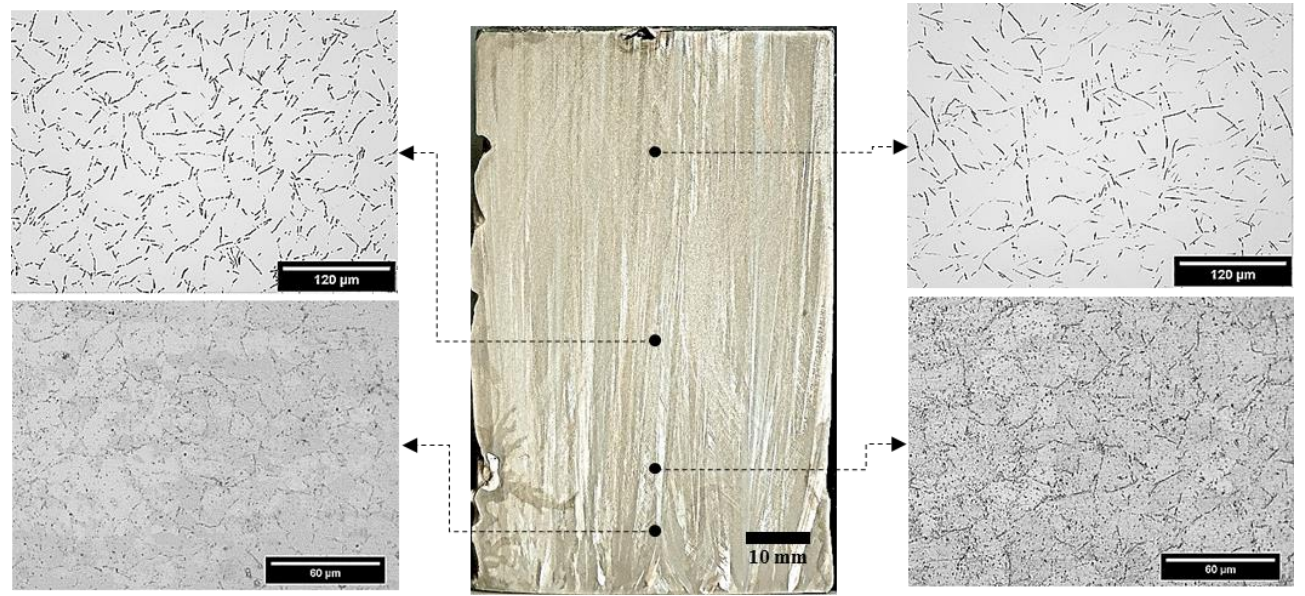

Figura 5.Macroestrutura e microestruturas em posições distintas obtidas para a liga Sn-0,2\%Ni.
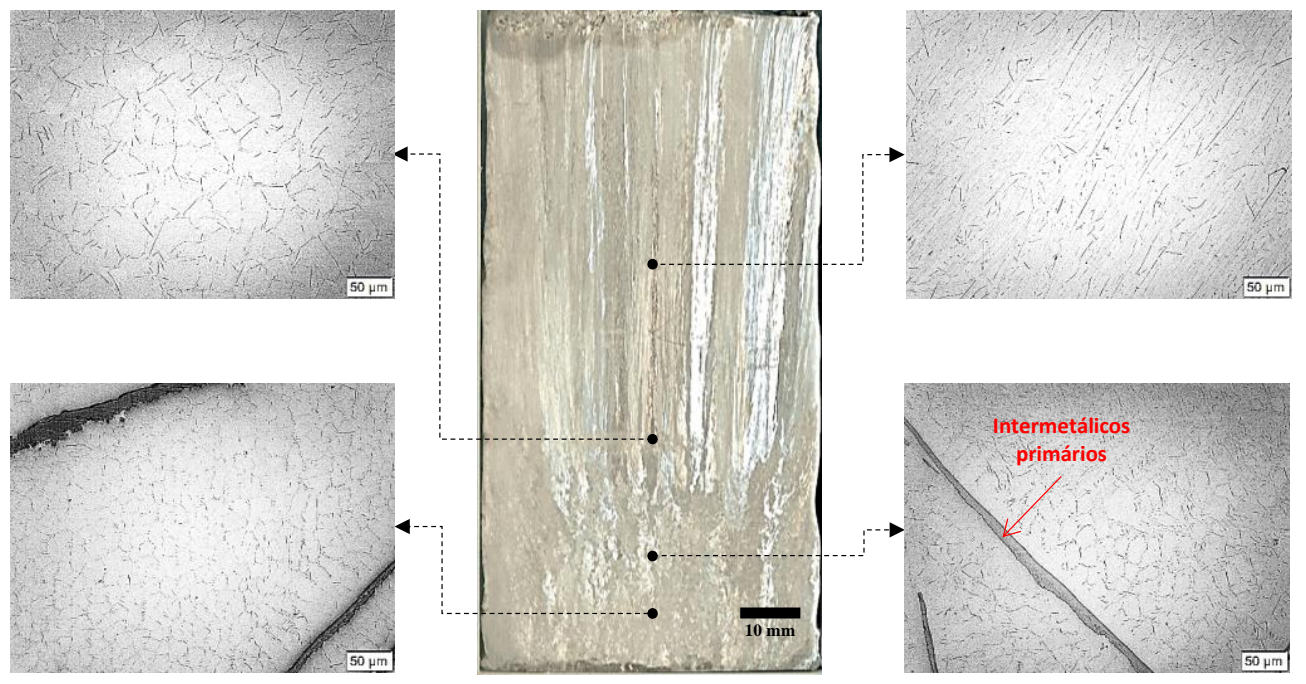

Figura 6.Macroestrutura e microestruturas em posições distintas obtidas para a liga Sn-0,5\%Ni. 
Na liga eutética $\mathrm{Sn}-0,2 \% \mathrm{Ni}$, a microestrutura é composta de células de $\beta$-Sn (Figura 5), e a partir da posição $50 \mathrm{~mm}\left(\dot{T}_{E<} 1,2{ }^{\circ} \mathrm{C} / \mathrm{s}\right)$, há uma zona de transição célula/dendrita, passando a coexistirem as duas morfologias. Normalmente, células evoluem para dendritas com aumento da velocidade de solidificação [7], mas os presentes resultados mostram o inverso. A chamada transição reversa observada no presente trabalho já foi descrita em outras ligas metálicas, como Sn-5,5\%Sb, Al$3 \% \mathrm{Mg}-1 \% \mathrm{Si}$, Sn-0,7\%Cu e aço AISI 304 [17-20]. Nessas ligas citadas, foi observado que o aumento da taxa de resfriamento favorecia a morfologia celular, e a mudança para dendritas ocorria com a redução de $\dot{T}$. No caso da liga Sn-0,7\%Cu processada por atomização por impulso, o valor crítico para a formação de células foi de $12 \stackrel{\circ}{\circ} / \mathrm{s}$, aproximadamente, 10 vezes o valor encontrado para a liga $\mathrm{Sn}-0,2 \% \mathrm{Ni}$ solidificada direcionalmente. No entanto, para a liga Sn-5,5\%Sb também solidificada direcionalmente, ocorreu a formação de células para taxas maiores que $1,2{ }^{\circ} \mathrm{C} / \mathrm{s}$, mesmo valor encontrado neste trabalho.

O crescimento de células em baixos valores de $\grave{T}$ na liga $\mathrm{Sn}-0,2 \% \mathrm{Ni}$ pode estar relacionado com a migração de $\mathrm{Fe}$, a partir da chapa de aço do molde, para as posições iniciais do molde. Por meio de análises de espectroscopia de energia dispersiva (EDS-MEV), foi encontrada significativa concentração de Fe até a posição 10 mm (Figura7.a). No trabalho de Canté et al. [21], a adição de 1\% de Fe na liga Al$1 \% \mathrm{Ni}$ impediu a formação de dendritas. Considerando mesmos valores de taxa de resfriamento, a liga ternária apresenta morfologia celular, enquanto que 0 crescimento de dendritaspredomina na liga binária.Dessa forma, na liga $\mathrm{Sn}-0,2 \% \mathrm{Ni}$, o Fe pode estar estabilizando as células em baixas taxas de resfriamento.

Nos contornos das células, a estrutura eutética é composta por $\beta-S n$ e o intermetálico metaestável $\mathrm{NiSn}_{4}$ [22-23], conforme a análise por EDS-MEV (Figura $7 a)$, divergindo do diagrama de fases, onde era previsto uma mistura $\beta-\mathrm{Sn}+\mathrm{Ni}_{3} \mathrm{Sn}_{4}$. Ao trabalhar com ligas do sistema $\mathrm{Sn}-\mathrm{Ni}$, variando a concentração de $\mathrm{Ni}$ entre $0,03 \mathrm{e}$ $0,45 \%$, Belyakov e Gourlay [14] verificaram que nas ligas hipoeutéticas e eutética, a estrutura eutética era formada por $\beta-\mathrm{Sn}$ e $\mathrm{NiSn}_{4}$, com uma pequena fração de $\mathrm{Ni}_{3} \mathrm{Sn}_{4}$ em algumas regiões. Para os autores, no sistema $\mathrm{Sn}-\mathrm{Ni}$, a precipitação das fases pode ser regida pelo crescimento cristalográfico, fazendo com que uma determinada combinação de interfaces cresça preferencialmente. Nesse sentido, NiSn 4 possui alta anisotropia na energia superficial, configurando uma associação mais forte com a interface do $\beta$-Sn durante o crescimento do eutético.

(a)

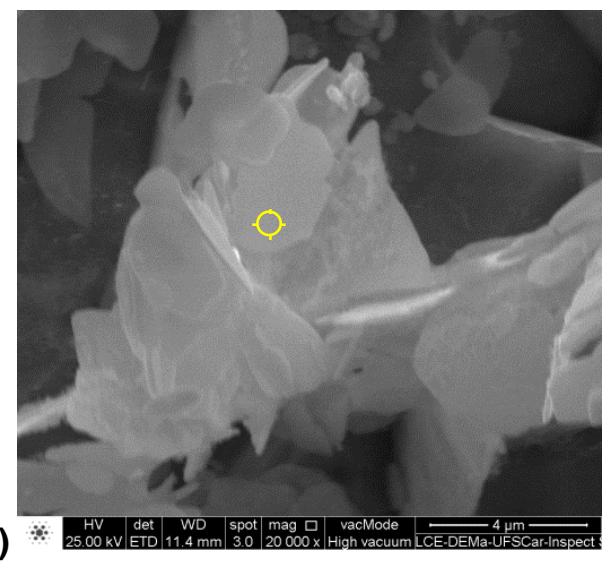

\begin{tabular}{crr} 
Element & Wt $\%$ & At \% \\
\hline C K & 2.37 & 17.71 \\
FeL & 6.34 & 10.20 \\
SnL & 80.64 & 60.98 \\
NiK & 5.44 & 8.31 \\
CuK & 0.55 & 0.78 \\
PbL & 4.66 & 2.02 \\
Total & 100.00 & 100.00
\end{tabular}




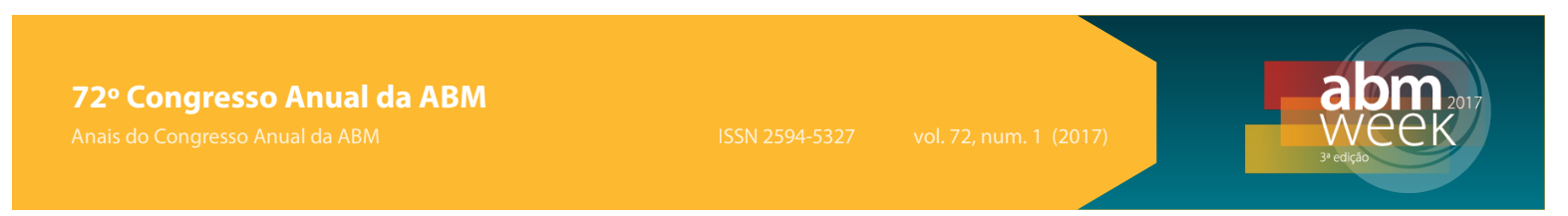

(b)

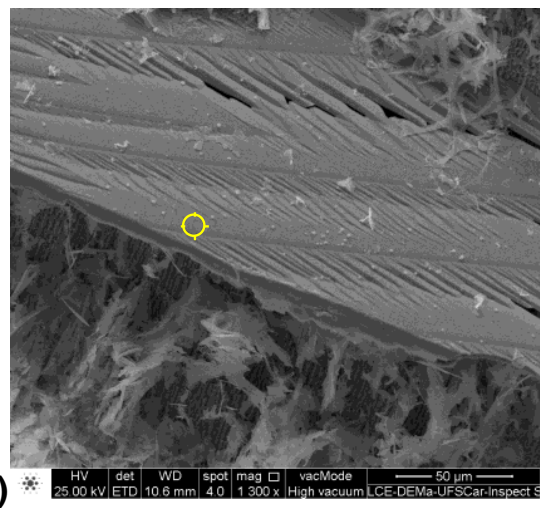

\begin{tabular}{crr} 
Element & Wt $\%$ & \multicolumn{1}{c}{ At \% } \\
\hline SnL & 74.99 & 59.70 \\
FeK & 0.57 & 0.96 \\
NiK & 24.45 & 39.34 \\
Total & 100.00 & 100.00
\end{tabular}

Figura 7.a) Análises por MEV-EDS dos intermetálicos presentes no contorno das células da liga Sn$0,2 \% \mathrm{Ni}\left[\mathrm{NiSn} n_{4}\right]$ e b) compondo a fase primária da liga $\mathrm{Sn}-0,5 \% \mathrm{Ni}_{[}\left[\mathrm{Ni}_{3} \mathrm{Sn}_{4}\right]$.

Na liga hipereutética $\mathrm{Sn}-0,5 \% \mathrm{Ni}$ (Figura 6), as fases primárias (intermetálicos ricos em $\mathrm{Ni}$ - $\mathrm{Ni}_{3} \mathrm{Sn}_{4}$ - Figura 7.b) precipitaram na temperatura liquidus, reduzindo a concentração de Ni no líquido da frente de solidificação e levando à formação de células ricas em Sn na temperatura eutética. Por consequência, devem-se associar as fases primárias (Figura 7.b) com $\dot{T}_{\llcorner}$e, assim como na liga Sn-0,2\%Ni, a estrutura celular com $\dot{T}_{\mathrm{E}}$.

Células de $\beta$-Sn estão presentes até a posição $30 \mathrm{~mm}\left(\dot{T}_{E}=1,4^{\circ} \mathrm{C} / \mathrm{s}\right)$, ocorrendo uma transição do tipo célula-placa em $40 \mathrm{~mm}\left(\dot{\mathrm{T}}_{\mathrm{E}}=1,0^{\circ} \mathrm{C} / \mathrm{s}\right)$, e na posição $60 \mathrm{~mm}\left(\dot{T}_{\mathrm{E}}=\right.$ $0,6^{\circ} \mathrm{C} / \mathrm{s}$ ), a morfologia do $\beta$-Sn é completamente constituída por placas. Outros trabalhos na literatura apresentaram estas microestruturas celulares do tipo placas para ligas a base de zinco, cujas taxas de resfriamento são superiores a 10K/s [24].

Nas posições iniciais (5 e $10 \mathrm{~mm}$, com $\dot{T}_{L} \geq 16,7^{\circ} \mathrm{C} / \mathrm{s}$ ) da liga $\mathrm{Sn}-0,5 \% \mathrm{Ni}$, duas fases primárias podem ser encontradas com três morfologias diferentes (Figura 8.a): uma fase mais escura na forma de placas alongadas e blocos facetados (indicada em azul) e uma fase mais clara com geometria complexa (indicada em vermelho).Pela análise de EDS-MEV (Figura 7.b), a fase mais escura é o intermetálico $\mathrm{Ni}_{3} \mathrm{Sn}_{4}$. Para posições mais distantes da interface metal/molde, ou seja, com a redução da taxa de resfriamento, a fase clara com geometria complexa se degenera em agulhas, enquanto que as placas continuam a existir e a fração de blocos facetados tende a diminuir. Entre as posições 20 e $25 \mathrm{~mm}$, não há presença de blocos facetados, apenas placas alongadas e agulhas. $E$ a partir da posição $30 \mathrm{~mm}$, a fase mais clara não se forma, os blocos facetados voltam a aparecer e a quantidade de placas diminui (Figura 8.b). Estes resultados estão de acordo com o trabalho de Belyakov e Gourlay [14], no qual os autores constataram que na solidificação de ligas Sn-Ni hipereutéticas, ocorre a formação dos intermetálicos $\mathrm{Ni}_{3} \mathrm{Sn}_{4}$ e $\mathrm{NiSn}_{4}$ como fase primária. Baixas taxas de resfriamento $\left(\dot{T}=0,02{ }^{\circ} \mathrm{C} / \mathrm{s}\right.$ ) induziam a formação de apenas $\mathrm{Ni}_{3} \mathrm{Sn}_{4}$, porém, o aumento da taxa de resfriamento favorecia a formação do intermetálico $\mathrm{NiSn}_{4}$. Além disso, a presença de Fe na liga, formando o intermetálico $\mathrm{FeSn}_{2}$, contribui para a precipitação do $\mathrm{NiSn}_{4}$ [25]. 


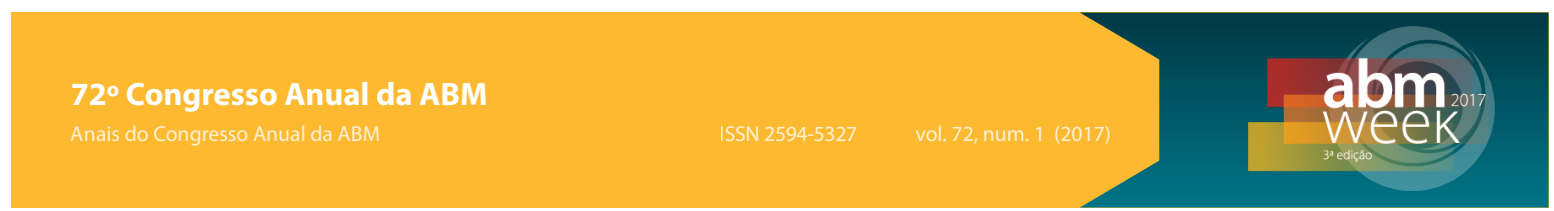

(a)

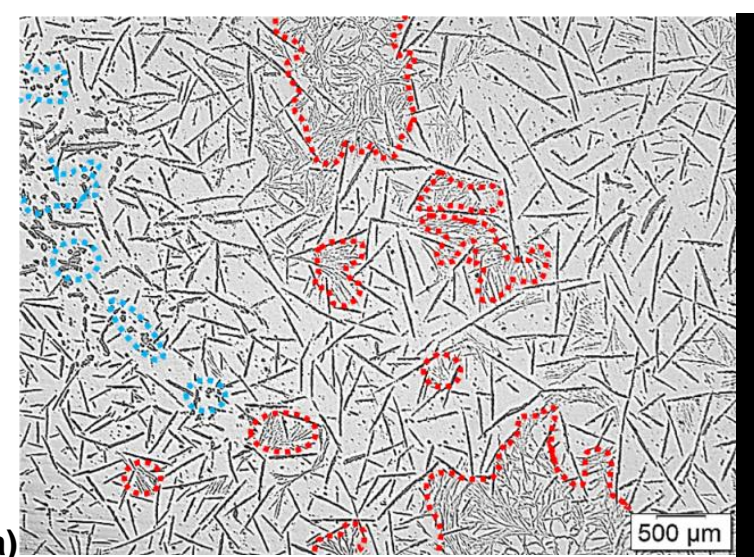

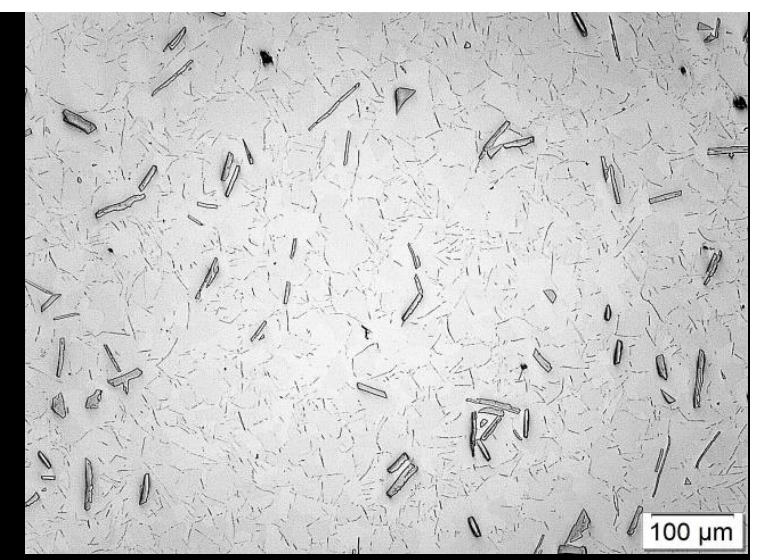

Figura 8. Microestrutura transversal da liga Sn-0,5\%Ni: Posição a partir da base refrigerada a) $5 \mathrm{~mm}$ e b) $40 \mathrm{~mm}$.

Os espaçamentos celulares $\left(\lambda_{c}\right)$ em função da taxa de resfriamento e da velocidade de solidificação estão representados nas Figuras 9 e 10, respectivamente. Os pontos nos gráficos representam a média do espaçamento microestrutural que foi determinado experimentalmente e seus respectivos desvios padrão. Devido à ausência de regularidade dos intermetálicos da liga $\mathrm{Sn}-0,5 \% \mathrm{Ni}$, não foi possível medir o espaçamentos dessas fases.

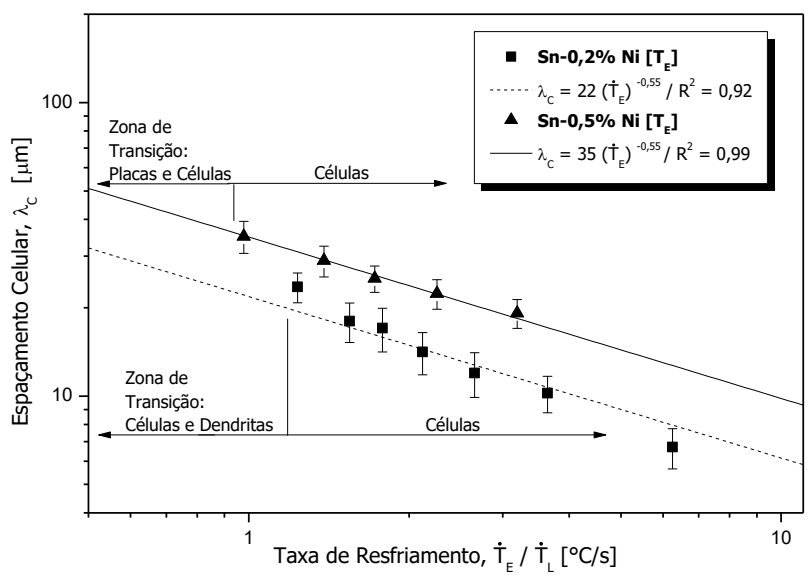

Figura 9.Correlações entre o espaçamento celular $\left(\lambda_{C}\right)$ e a taxa de resfriamento $\left(T_{E}\right)$ das ligas Sn-Ni.

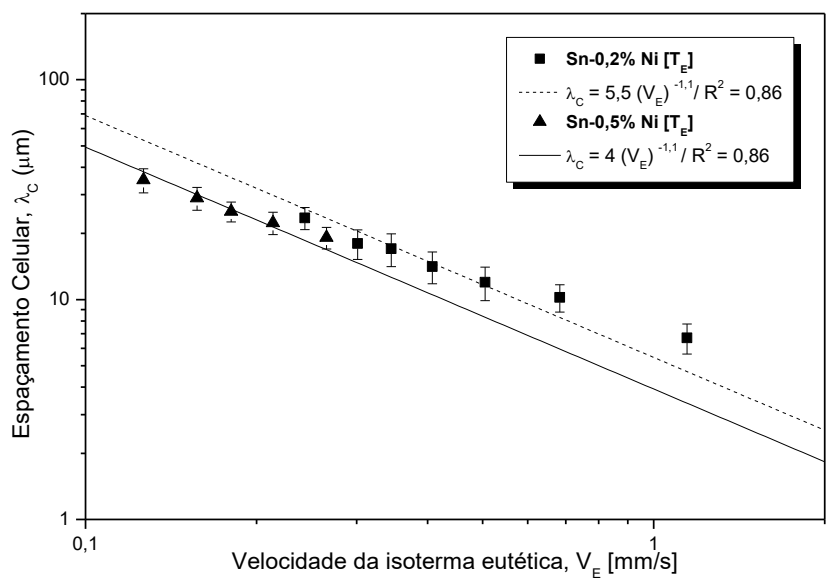

Figura 10. Correlações entre o espaçamento celular $\left(\lambda_{C}\right)$ e a velocidade da isoterma eutética $\left(V_{E}\right)$ das ligas $\mathrm{Sn}-\mathrm{Ni}$. 
As relações experimentais tipo potência obtidas apresentam expoentes -0,55 e -1,1 e representam as variações de $\lambda_{c}$ com a taxa de resfriamento e velocidade da isoterma da frente eutética, respectivamente.

Para fins de correlações entre parâmetros térmicos e espaçamento celular e, portanto, baseado na temperatura de transformação eutética, pode-se comparar os resultados experimentais verificados das ligas eutética $\mathrm{Sn}-0,2 \% \mathrm{Ni}\left[\mathrm{T}_{\mathrm{E}}\right]$ e hipereutética $\mathrm{Sn}-0,5 \% \mathrm{Ni}\left[\mathrm{T}_{\mathrm{E}}\right]$. De acordo com as relações do tipo $\lambda_{c} \times$ Tं (Figura 9), verificou-se que para qualquer taxa de resfriamento (por exemplo, $\dot{\top} \sim 1,0^{\circ} \mathrm{C} / \mathrm{s}$ ), os valores de $\lambda_{c}$ obtidos para $\mathrm{Sn}-0,5 \% \mathrm{Ni}(35,0 \mu \mathrm{m})$ são superiores quando comparados com os valores encontrados para a liga Sn-0,2\% Ni $(23,5 \mu \mathrm{m})$.

Apesar do espaçamento celular diminuir com o aumento da velocidade da frente eutética (Figura10), aparentemente a magnitude do espaçamento celular não é significativamente afetada pelo aumento do teor de $\mathrm{Ni}$ de $0,2 \%$ para $0,5 \%$ quando se observam as evoluções do tipo $\lambda_{\mathrm{C}} \times \mathrm{V}_{\mathrm{E}}$.

\section{CONCLUSÕES}

As conclusões que se seguem podem ser baseadas nos resultados das investigações experimentais oriundas deste trabalho:

- As evoluções da velocidade da frente eutética/líquidus e da taxa de resfriamento com a posição mostraram que os valores de $v$ e Tं diminuem à medida que distância da base refrigerada aumenta, sendo as maiores taxas de resfriamento da frente eutética obtidas para a liga hipereutética $\mathrm{Sn}-0,5 \% \mathrm{Ni}\left(\dot{T}_{L}=36^{\circ} \mathrm{C} / \mathrm{s}\right.$ contra $\left.\dot{T}_{E}=7^{\circ} \mathrm{C} / \mathrm{s}\right)$;

- As macroestruturas dos lingotes $\mathrm{Sn}-0,2 \% \mathrm{Ni}$ e $\mathrm{Sn}-0,5 \% \mathrm{Ni}$ confirmaram a direcionalidade do processo de solidificação, uma vez que apresentaram, predominantemente, grãos colunares;

- As análises microestruturais mostraram que um crescimento celular composto por uma matriz de $\beta$-Sn prevaleceu ao longo das ligas $\mathrm{Sn}-0,2 \% \mathrm{Ni}$ e $\mathrm{Sn}-0,5 \% \mathrm{Ni}$, até as posições $50 \mathrm{~mm}\left(\dot{T}_{E}>1,2^{\circ} \mathrm{C} / \mathrm{s}\right)$ e $30 \mathrm{~mm}\left(\dot{T}_{E>} 1,4^{\circ} \mathrm{C} / \mathrm{s}\right)$, respectivamente, a partir da interface metal/molde. Notou-se ainda que a transição morfológica celular /dentritica ocorreu apenas para a liga eutética, à medida que para a liga hipereutética as células regulares deram origem àuma morfologia do tipo placas;

- Para as duas ligas, a região eutética é composta por $\beta-S n$ e o intermetálico NiSn4, enquanto que na liga hipereutética, duas fases primárias se formaram $\left(\mathrm{NiSn}_{4}\right.$ e $\mathrm{Ni}_{3} \mathrm{Sn}_{4}$ ), com diferentes morfologias de acordo com a taxa de resfriamento;

- A variação dos espaçamentos celulares $\left(\lambda_{c}\right)$ em função da taxa de resfriamento e da velocidade da frente eutética para as ligas Sn-0,2 e 0,5\%Ni foi caracterizada por expoentes experimentais de $-0,55$ e $-1,1$, respectivamente. Os maiores espaçamentos intercelulares foram encontrados para a liga hipereutética $\mathrm{Sn}-0,5 \% \mathrm{Ni}$ $\left[\lambda_{c}(\mathrm{Sn}-0,5 \% \mathrm{Ni})=35,0 \mu \mathrm{m}\right.$ contra $\left.\left.\lambda_{c}(\mathrm{Sn}-0,2 \% \mathrm{Ni})=23,5 \mu \mathrm{m}\right)\right]$ quando observa-se a evolução do tipo $\lambda_{c} \times \dot{T}_{E}$.

\section{Agradecimentos}

Os autores agradecem o apoio financeiro concedido pelos órgãos de fomento: Coordenação de Aperfeiçoamento de Pessoal de Nível Superior - CAPES, Conselho Nacional de Desenvolvimento Científico e Tecnológico - CNPq e Fundação de Amparo á Pesquisa do Estado de São Paulo - FAPESP (Projeto Auxilio FAPESP N. 2015/11863-5), bem como aos programas de pós-graduação: Programa de PósGraduação em Ciência e Engenharia de Materiais da Universidade Federal de São 
Carlos - PPGCEM/UFSCar e Programa de Pós-Graduação em Engenharia Mecânica da Faculdade de Engenharia Mecânica - PPGEM/FEM.

\section{REFERÊNCIAS}

$1 \mathrm{Ma} \mathrm{H}$, Suhling JC. A review of mechanical properties of lead-free solders for electronic packaging. Journal Materials Science. 2009;44(5):1141-1158.

2 Wu CML, Yu DQ, Law CMT, Wang L. Properties of lead-free solder alloys with rare earth elements aditions. Materials Science and Engineering: R: Reports. 2004;44(1):144.

3 McCartney DG, Hunt JD. Measurements of cells and primary dendrite arms pacing in directionally solidified aluminium alloys. Acta Metallurgica. 1981;29(11):1851-1863.

4 Silva BL, Garcia A, Spinelli JE.Complex eutectic growth and Bi precipitation in ternary Sn-Bi-Cu and Sn-Bi-Ag alloys. Journal of Alloys and Compounds. 2017;691:600-605.

5 Osório WR, Peixoto LC, Garcia LR, Mangelinck-Noël N, Garcia A. Microstructure and mechanical properties of $\mathrm{Sn}-\mathrm{Bi}, \mathrm{Sn}-\mathrm{Ag}$ and $\mathrm{Sn}-\mathrm{Zn}$ lead-free solder alloys. Journal of Alloys and Compounds. 2013;572:97-106.

6 Moura ITL, Silva CLM, Cheung N, Goulart PR, Garcia A, Spinelli JE. Cellular to dendritic transition during transient solidification of a eutectic $\mathrm{Sn}-0.7 \mathrm{wt} \% \mathrm{Cu}$ solder alloy. Materials Chemistry and Physics. 2012;132 (1):203-209.

7 Garcia A. Solidificação: Fundamentos e Aplicações. Campinas: Editora da Unicamp; 2007.

8 Abd El-Rehima AF, Zahrana HY. Investigation of microstructure and mechanical propertiesof Sn-xCu solder alloys. Journal of Alloys and Compounds. 2017;695:3666367.

9 Yang L, Zhang Y, Dai J, Jing Y, Ge J, Zhang N. Microstructure, interfacial IMC and mechanica lproperties of $\mathrm{Sn}-0.7 \mathrm{Cu}-\mathrm{XAl}(\mathrm{x}=0-0.075)$ lead-free solder alloy. Materials and Design. 2015;67:209-216.

10 Belyakov S.A., Xian J.W.,Sweatman K.,Nishimura T., Akaiwa T., Gourlay C.M. Influence of bismuth on the solidification of $\mathrm{Sn}-0.7 \mathrm{Cu}-0.05 \mathrm{Ni}-\mathrm{xBi} / \mathrm{Cu}$ joints. Journal of Alloys and Compounds. 2017;701:321-334.

11 Böyük U, Maraşli N. Dependency of eutectic spacings and microhardness on the temperature gradient for directionally solidified $\mathrm{Sn}-\mathrm{Ag}-\mathrm{Cu}$ lead-free solder. Materials Chemistry and Physics.2010;119(3):442-448.

12 Pereira PD, Spinelli JE, Garcia A. Combined effects of Ag content and cooling rate on microstructure and mechanical behavior of $\mathrm{Sn}$ Ag Cu solders. Materials and Design. 2013;45:377-383.

13 Osório WR, Leiva DR, Peixoto LC, Garcia LR, Garcia A. Mechanical properties of Sn Ag lead-free solder alloys based on the dendritic array and Ag3Sn morphology. Journal of Alloys and Compounds. 2013;562:194-204.

14 Belyakov S.A., Gourlay C.M.NiSn4 formation during the solidification of Sn-Ni alloys. Journal of Alloys and Compounds. 2012;25:48-59.

15 Rosa DM, Spinelli JE, Ferreira, IL, Garcia A. Cellular/dendritic transition and microstructure evolution during transient directional solidification of $\mathrm{Pb}-\mathrm{Sb}$ alloys. Metallurgical and Materials Transactions A. 2008;39(9):2161-2174.

16 Gündüz M; Çadirli, E. Directional solidification of aluminium-copper alloys. Materials Science and EngineeringA.2002; 327(2): 167-185.

17 Dias M, Costa T, Rocha O, Spinelli JE, Cheung N, Garcia A. Interconnection of thermal parameters, microstructure and mechanical properties in directionally solidified $\mathrm{Sn}-\mathrm{Sb}$ lead-free solder alloys. Materials Characterization. 2015;106:52-61.

18 Brito C, Vida T, Freitas E, Cheung N, Spinelli JE, Garcia A. Cellular/dendritic arrays and intermetallic phases affecting corrosion and mechanical resistances of na Al-Mg-Si alloy. Journal of Alloys and Compounds. 2016;673:220-230. 
19 Moreno GR, Silva BL, Bogno A, Henein H, Spinelli JE. Microstructure-property relations in as-atomized and as-extruded $\mathrm{Sn}-\mathrm{Cu}(-\mathrm{Ag})$ solderalloys. Journal of Alloys and Compounds. 2016;680:259-267.

20 Fu JW, Yang YS, Guo JJ, Tong WH. Effect of cooling rate on solidification microstructures in AISI 304 stainless steel. Materials Science and Technology. 2008;24(8):941-944.

21 Canté MV, Brito C, Spinelli JE, Garcia A. Interrelation of cell spacing, intermetallic compounds and hardness on a directionally solidified Al-1.0Fe-1.0Ni alloy. Materials and Design. 2013;51:342-346.

22 Schimpf C, Kalanke P, Shang SL, Liu ZK, Leineweber A. Stacking disorder in metastable NiSn4. Materials and Design. 2016;109:324-333.

23 Wang $\mathrm{CH}$, Kuo $\mathrm{C}$, Chen $\mathrm{H}$, Chen S. Effects of current density and temperature on $\mathrm{Sn} / \mathrm{Ni}$ interfacial reactions under current stressing. Intermetallics. 2011;19(1):75-80.

24 Dias M, Brito C,Bertelli F, Garcia A. Cellular growth of single-phase Zn-Ag alloys unidirectionally solidified. Materials Chemistry and Physics. 2014;143:895-899.

25 Belyakov S. A., Gourlay C.M. Role of Fe impurities in the nucleation of metastable $\mathrm{NiSn}_{4}$. Intermetallics. 2013;37:32-41. 